\title{
Correction to: Influence of time-dependent seismic hazard on structural design
}

\author{
Andrea Dall'Asta ${ }^{1}$ (D) Hamed Dabiri ${ }^{2}$ (D) $\cdot$ Emanuele Tondi $^{2}$ (D) $\cdot$ Michele Morici $^{1}$ (i) \\ Published online: 6 September 2021 \\ (c) Springer Nature B.V. 2021
}

\section{Correction to: Bulletin of Earthquake Engineering (2021) 19:2505-2529 https://doi.org/10.1007/s10518-021-01075-3}

This correction is published as author name typo was found in the original article and should be read as Michele Morici instead of Michele Morci.

Original article has been updated.

Publisher's Note Springer Nature remains neutral with regard to jurisdictional claims in published maps and institutional affiliations.

The original article can be found online at https://doi.org/10.1007/s10518-021-01075-3.

Michele Morici

michele.morici@unicam.it

1 School of Architecture and Design (SAAD), University of Camerino, Viale della Rimembranza 9, 63100 Ascoli Piceno, Italy

2 School of Science and Technologies - Geology Division, University of Camerino, Via Gentile III, Da Varano, 62032 Camerino, Italy 